\title{
The Outstanding Role of Iranian Military Forces in the Fight Against COVID-19
}

\author{
Yalda Mousazadeh ${ }^{1, *}$ \\ ${ }^{1}$ Iranian Center of Excellence in Health Management, School of Management and Medical Informatics, Tabriz University of Medical Sciences, Tabriz, Iran \\ "Corresponding author: Iranian Center of Excellence in Health Management, School of Management and Medical Informatics, Tabriz University of Medical Sciences, Tabriz, \\ Iran.Email: y.mousazadeh@yahoo.com
}

Received 2020 December 22; Accepted 2021 March 03.

Keywords: COVID-19, Military Force, Armed Force

\section{Dear editor,}

On December 13, 2019, the Wuhan Municipal Health Commission, China, reported cases of pneumonia with unknown causes following an outbreak in Wuhan South China seafood wholesale market. More studies introduced and reported a new coronavirus as the cause of respiratory symptoms in these cases (1). The virus caused signs and symptoms similar to the severe acute respiratory syndrome (SARS) and Middle East respiratory syndrome (MERS) and could be transferred through close humanto-human contact. In recent year, COVID-19 became the most significant public health crisis in the world, following MERS and SARS (2).

Cases were reported in other countries besides China. With the spread of the virus to other countries and the announcement of an emergency situation, most of the world's countries implemented extreme safety measures. The disease's spread was such that the World Health Organization (WHO) confirmed the outbreak as a pandemic on March 11, 2020 (3). Until November 29, 2020, the WHO announced 77234607 confirmed cases of COVID-19 and a total of 1700961 deaths (4).

In many countries, the health system is known as the front line and the main sector in coping with public health crises. Besides the decisions made at national and provincial levels, the participation of all parts of the community, including public and governmental organizations and institutions, can considerably help to control the disease. At this point, armed forces and military complexes in different countries can have a significant role in fighting against the COVID-19 disease, given their expertise, readiness, and scientific ability. Because of their special training and characteristics, military organizations and their affiliated forces have good maneuverability and can serve in various roles, including rescue operations, treating patients, transferring the injured and those in need of help in affected areas, etc. (5).

The actions of the military have been evident in various countries since the early days of the Corona outbreak. For instance, as the source of the disease, China started a massive campaign against Corona. During the Chinese military fight against the virus, many troops and huge supplies were provided by the organization. The Chinese military has been involved in implementing quarantine and relief operations, as well as distributing supplies and other necessities in quarantined areas from the beginning of the outbreak. Moreover, the Chinese military focused many of its research efforts on developing the vaccines and drugs needed to fight the virus.

In Sweden, a team of the army's chemical, microbial and atomic warfare forces, along with a military laboratory, started working with the Swedish university to develop rapid detection and diagnosis method of the virus. In Italy, as a country with a high prevalence of coronavirus and related mortality, the military and police accepted the responsibility for enforcing quarantine rules and monitoring the implementation of curfews to prevent the spread of the virus. Furthermore, British and the USA armies were on standby to act if the states turned into critical conditions. The French Military Centre that works on the fields of epidemiology and public health provided some essential information required to the decision-making process. The emergency departments of the Paris Fire Brigade and Marseille offered prehospital services to COVID-19 patients. Several military educational hospitals collaborated with regional health centers. The biomedical research institute affiliated with the military executed diagnostics and participated in many research projects by presenting updated 
scientific literature and expert views on COVID-19 (6).

It seems that the armed forces of our country (Iran) have fulfilled a more prominent and significant role compared to other countries' military sections in helping and cooperating with the government and executive institutions. All Iran's military forces, including the army, Revolutionary Guard Corps, Ministry of Defense, and the police, have been involved in fighting the coronavirus. One of the first divisions of armed forces that participated in the battle was the Ministry of Defense and Armed Forces Support. During the outbreak, this ministry contributed to disease prevention by producing and distributing face masks and disinfectants. Efforts to produce diagnostic kits have been among prominent actions of Iran's Ministry of Defense.

Given the valuable experiences from the time of Iran's Holy Defense in coping with various diseases and injuries, the Army and Islamic Revolutionary Guard Corps formed a camp to deal with the disease. Providing medical personnel and establishing clinics and mobile hospitals in various areas affected by the disease to obviate the shortage of hospital beds, as well as providing some of the equipment needed by hospitals, were among important measures taken by these forces. They appropriately fulfilled their role in reducing the pressure on the country's healthcare system. Furthermore, the contamination teams of the Islamic Revolutionary Guard Corps and Army took responsibility for cleaning and disinfecting the environment and various places in multiple cities, including the northern regions that had countless infected people. These forces have also provided food and shelter for vulnerable families and individuals since the corona outbreak. The project of producing the Corona therapeutic medicine has been started with the cooperation of the Ministry of Health and Islamic Revolutionary Guard Corps Deputy for Research and Industry at the Genetics Center of Baqiyatallah University of Medical Sciences, which appears to be very promising.
The above-mentioned shows that the Corona outbreak has rendered the entire armed forces of Iran to be integrated together. These forces have mobilized all their power, capacities, and potential to aid the Ministry of Health, as the body in charge of the country's health, to defeat this virus with minimal casualties and injuries.

\section{Footnotes}

Authors' Contribution: None to declare.

Conflict of Interests: There is no conflict of interest.

Funding/Support: There is no funding/support.

\section{References}

1. Doshmangir L, Mahbub Ahari A, Qolipour K, Azami S, Kalankesh L, Doshmangir P, et al. [East Asia's strategies for effective response to COVID-19: Lessons learned for Iran]. Manage Strat Health Syst. 2020;4(4):370-3. Persian. doi: 10.18502/mshsj.v4i4.2542.

2. Peeri NC, Shrestha N, Rahman MS, Zaki R, Tan Z, Bibi S, et al. The SARS, MERS and novel coronavirus (COVID-19) epidemics, the newest and biggest global health threats: what lessons have we learned? Int J Epidemiol. 2020;49(3):717-26. doi: 10.1093/ije/dyaa033. [PubMed: 32086938]. [PubMed Central: PMC7197734].

3. Eurosurveillance Editorial Team. Note from the editors: World Health Organization declares novel coronavirus (2019-nCoV) sixth public health emergency of international concern. Euro Surveill. 2020;25(5) doi: 10.2807/1560-7917.ES.2020.25.5.200131e. [PubMed: 32019636]. [PubMed Central: PMC7014669].

4. World Health Organization. Coronavirus disease (COVID-19) Weekly Epidemiological Update and Weekly Operational Update. Geneva, Switzerland: World Health Organization; 2021, [updated Apr 2021; cited 29th Nov 2020]. Available from: https://www.who.int/emergencies/ diseases/novel-coronavirus-2019/situation-reports.

5. Ghanjal A. [Role of the military forces and related medical personnel in rescue services in case of unexpected events and disasters]. Mil Med. 2002;4(3):189-95. Persian.

6. Pasquier P, Luft A, Gillard J, Boutonnet M, Vallet C, Pontier JM, et al. How do we fight COVID-19? Military medical actions in the war against the COVID-19 pandemic in France. BMJ Mil Health. 2020. doi: 10.1136/bmjmilitary-2020-001569. [PubMed: 32759228]. 